\title{
Face-to-Face and Online Classes in a Technology Management Program: A Comparative Study
}

\author{
Noemi Mendoza-Diaz, Bin Mai, Jessica Martinez, Sami Jabarkhail, \& \\ Deyanira Garcia
}

\begin{abstract}
This study compared students' expectations, perceptions, and grades in two undergraduate technology management courses at a university in the United States. One course was a technical course taught by a single instructor in an online course section and in a face-to-face section, and the second was a nontechnical course taught by a different instructor in an online and in a face-toface section. Different concerns were evident between online and face-to-face students and between those in a technical or nontechnical section of a course. For the technical course sections, grades were higher in the online section.
\end{abstract}

Keywords: online education; student expectations; technology management

The advent of technology in the classroom, paired with the development of the Internet, has marked a new era in the way universities offer undergraduate education. Online instruction has increased exponentially, to the extent that almost all universities offer at least one type of program in the online format. However, technical and engineering programs have delayed the incorporation of online instruction because of the widespread belief that STEM content is not easily taught in formats other than face-to-face (F2F). The most compelling reason is the nature of their curriculum in which laboratory experimentation is central (Bourne et al., 2005). Another challenging fact to note is the higher rates of attrition in STEM fields for the online formats of instruction, around 30\% to $40 \%$ (Wladis et al., 2015).

Technology management, for obvious reasons, is one type of program that has benefitted from the availability of online instruction. Most of these programs are traditionally taught in colleges of engineering or business. It is in the colleges of business that most management of information systems programs reside; this affords opportunities for alternative modes of instruction available to nontraditional audiences. However, the existing literature lacks sufficient insights into how students perceive these two major modes of course delivery, and few studies have investigated the impacts of delivery modes for technical and nontechnical courses.

Mendoza-Diaz, N., Mai, B., Martinez, J., Jabarkhail, S., \& Garcia, D. (2020). Face-toface and online classes in a technology management program: A comparative study. Journal of Technology Education, 32(1), 21-34. https://doi.org/10.21061/jte.v32i1.a.2 
That is the gap this study is attempting to fill. This article presents an exploration of online and face-to-face modes of instruction in a Technology Management undergraduate program for technology-based and non-technologybased content. The program offers flexibility in that the same two classes are offered in both formats every semester to freshman and sophomore students. Also, the program is housed in the college of education, which provides an additional layer of complexity worth investigating.

\section{Literature Review}

Ernst (2008) compared traditional and hybrid online groups from the perspective of students' performance (a test) and perceptions (online survey). The course was part of a Technology Education program and focused on imaging technology. He found that both formats, traditional and hybrid online, had similar student learning outcomes. Previously, Ndahi (2006) studied the extent to which laboratory courses were delivered via distance education in technology and engineering programs in the United States and the United Kingdom via a purposive sample. At the time, he found that $48.8 \%$ of technology and engineering departments sampled offered distance education courses, and of those, $12.2 \%$ were laboratories. It is important to note the difficulty he found in the implementation of hands-on activities in online laboratories because hands-on activities are central to engineering and technology programs, as noted above.

Huang et al. (2015) described the difficulty of providing equivalent experiences between an online mechanical engineering laboratory and an onsite laboratory but found similar learning outcomes in students. Bourne et al. (2005) and Froyd et al. (2012) claimed no significant difference between online and oncampus engineering students, as measured by test scores. More recently, Saleheen et al. (2018) found an actual increase in students' performance when provided with an entry-level electric circuit online laboratory called VOLTA.

On the other hand, Bir (2019) found that online pedagogy had a negative effect on students' academic performance when compared with the traditionally taught group in a course on the mechanics of materials. Wladis et al. (2015) studied students who succeeded in online STEM classrooms and found that older students did significantly better, women did significantly worse, and Black and Hispanic students may do worse in STEM courses than their White and Asian peers in both online and face-to-face formats. Driscoll et al. (2012) talked about the never-ending debate between proponents and detractors of online education, noting the dangers of the "McDonaldization" in this format.

In a meta-analysis comparing distance education and classroom instruction, Bernard et al. (2004) found no differences between formats across multiple disciplines. These findings seem to point to the themes that Downs (2014) identified as prevalent in the assessment of online undergraduate programs: "(a) informal feedback from the students and faculty, (b) student satisfaction surveys, 
[and] (c) student grades and performance information" (p. 1). These limiting assessment factors seem to contribute to the widespread idea that it is more the quality of the instruction and its design that really contributes to a successful online education experience rather than the format or medium of delivery. This is reinforced by exemplary cases such as Embry-Riddle Aeronautical University, which provides quality elements of a worldwide engineering program (Herron et al., 2012).

\section{Background and Research Question}

Early in the 21st century, the College of Education and Human Development at Texas A\&M University launched a visionary Technology Management (TCMG) undergraduate program housed in the Department of Educational Administration and Human Resource Development (EAHR), although technology management programs are usually housed in colleges of technology, engineering, or business. With the rapid expansion of computers in the classroom seen in the 90 s, the need to provide support to the new technologies in schools, including students, teachers, and administrators, brought about this program. Given the unique origin and location of this particular program, it integrates a human component into the highly technical degree plan. As its mission states, the program has a commitment "to advancing integrated knowledge of human development, management, and technology competencies within a dynamic and rapidly evolving environment through innovative teaching, research, and service" (Texas A\&M University, Department of Educational Administration and Human Resource Development, 2019).

The curriculum consists of general university courses in the first year, while following years are a combination of management, human resource development, and technology classes. Students majoring in technology management obtain a minor in business, provided by the Mays Business School at Texas A\&M University, and students from other programs also have the opportunity to obtain a minor in Technology Management. The TCMG program includes six mandatory human resource development classes, starting with EHRD 203: Foundations of HR Development, which is also taken by HRD majors. There are nine technology classes offered by the EAHR department, including TCMG 308: Security and Ethics in the Digital World.

The EHRD 203: Foundation of Human Resource Development class is devoted to facilitating a working knowledge of the field of Human Resource Development (HRD). Among many skills, at the end of the course, students should be able to: (1) describe the field of HRD and provide a historical perspective of its development; (2) describe a model of employee behavior and various motivational theories and discuss how knowledge, skill, ability, and attitude influence employee behavior; (3) discuss organizational learning, adult learning theory, and the role of learning styles and strategies in learning; (4) 
elaborate on the purposes and advantages of needs assessments and identify the attributes (all the way through to evaluation) of different kinds of HRD programs; (5) describe organization development and change in relation to models of change and OD theories; and (6) discuss diversity within the context of HRD (Texas A\&M University, 2018a).

The TCMG 308: Security and Ethics in the Digital World class is devoted to introducing: cybersecurity, analysis, threats, and risks from the environment; development of appropriate strategies to mitigate impact; ethics of extraordinary administrative access; ethics of digital forensics; and implications to society. Among many skills, at the end of the course, students should be able to:

(1) apply the different security technology for securing personal and business information systems and resources including Anti-virus, Firewalls, VPNs, IDS, cryptology-based security solution, access control, and others; (2) access and use information ethically and legally during oral and written communication while analyzing and discussing critical issues in information systems security; and (3) gain hands-on experience of some important information security tools. (Texas A\&M University, 2018b)

This study sought to understand the way that undergraduate students perceive online instruction in technical (TCMG 308) and nontechnical (EHRD 203) classes compared to their face-to-face counterparts. It also sought to understand how these perceptions relate to actual performance - grade obtained. Both classes, EHRD 203 and TCMG 308, are offered every semester in both formats, face-to-face and online. This study was designed to investigate the following research questions:

1. How do online instruction students' perceptions compare to equivalent face-to-face instruction for technical and nontechnical topics in a technology management program?

2. How does online instruction students' performance compare to equivalent face-to-face instruction for technical and nontechnical topics in a technology management program?

In order to address these questions, during the fall of 2018, two instructors had the opportunity to teach the same class in the two different formats, and data were collected for those classes. The analysis and findings are presented in this article.

\section{Research Methods}

This study used a mixed-methods approach with two phases. The first phase involved an online survey given at the beginning and the end of the fall 2018 semester to four student groups: (1) the Foundations of HRD face-to-face group, 
(2) the Foundations of HRD online group, (3) the Security and Ethics in the Digital World face-to-face group, and the (4) Security and Ethics in the Digital World online group. The second phase involved a statistical analysis of final grades for the four groups.

In the initial qualitative phase of the study, an online survey was provided to the students in a pre-post fashion. The survey items are shown in Table 1. The respondents of the surveys are shown in Table 2 . The survey was voluntary and did not request any demographic information. IRB approval was obtained, and confidentiality was maintained for all participants.

Table 1

Items in the Online Survey Applied to All Groups

\begin{tabular}{|c|c|}
\hline Presurvey items & Postsurvey items \\
\hline $\begin{array}{l}\text { 1. What do you expect from this } \\
\text { class? }\end{array}$ & $\begin{array}{l}\text { 1. Were your expectation for this } \\
\text { class met? Please elaborate. }\end{array}$ \\
\hline $\begin{array}{l}\text { 2. Do you have concerns about this } \\
\text { class? If so, what are they? }\end{array}$ & $\begin{array}{l}\text { 2. Do you have concerns about } \\
\text { this class? If so, what are they? }\end{array}$ \\
\hline 3. How do you feel about the & $\begin{array}{l}\text { 3. How do you feel about the } \\
\text { format (online) of this class? }\end{array}$ \\
\hline $\begin{array}{l}\text { 4. If you were to take this same } \\
\text { class in a different format, what } \\
\text { would be your expectations? }\end{array}$ & $\begin{array}{l}\text { class in a different format (face- } \\
\text { to-face), what would be your } \\
\text { expectations? }\end{array}$ \\
\hline $\begin{array}{l}\text { 5. What grade do you expect to } \\
\text { obtain at the end of this } \\
\text { semester? }\end{array}$ & $\begin{array}{l}\text { 5. What grade do you expect to } \\
\text { obtain at the end of this } \\
\text { semester? }\end{array}$ \\
\hline
\end{tabular}

Table 2

Number of Participants Returning Surveys

\begin{tabular}{lcccccc}
\hline & \multicolumn{2}{c}{ F2F } & & \multicolumn{2}{c}{ Online } \\
\cline { 2 - 3 } \cline { 5 - 6 } & Pre & Post & & Pre & Post \\
\hline Foundations of HRD & 39 & 30 & & 27 & 6 \\
Security and Ethics in the Digital World & 9 & 5 & & 10 & 5 \\
\hline
\end{tabular}

The final quantitative phase of the study was an analysis of final grades of the four groups. The focus of the analysis was the performance within the same content (technical and nontechnical) but in a different format (online vs. face-toface). The descriptive statistics of these groups are shown in Tables 6 and 7 and will be discussed later.

\section{Qualitative Analysis}


In order to answer the first research question, a qualitative analysis of students' perceptions was performed. Interpretive naturalistic inquiry (Lincoln $\&$ Guba, 1985), in the form of content analysis, was used as the initial method of research. Content analysis, as a form of qualitative analysis, looks at the perceptions of participants and creates categories of common assertions. If more details are provided on each category, subcategories are formed until a point of saturation is reached. This means that participants' prompts are exhaustively analyzed until they do not provide any new or relevant information (Creswell \& Poth, 2017; Holsti, 1969; Lincoln \& Guba, 1985). Two coders were used for the qualitative analysis. These coders met regularly with the first author of this paper; the interrater reliability for their analysis was $73 \%$, using Holsti's coefficient (Holsti, 1969).

Because the number of participants varied in the groups, the analysis was normalized based on the totality of participants per group, i.e., the percentage of respondents. This provided a statistic by which to compare groups. Categories from this content analysis that were shared by both classes and in both formats are shown in Table 3. Identification of common topics showed that some students in each of the face-to-face courses mentioned taking the course for the purpose of earning credit and for utilization in their future careers in the presurveys. It also showed that concerns, such as workload, were more prevalent in the technical class in both formats $(60 \%$ face-to-face cybersecurity in the postsurvey, $40 \%$ grading in the postsurvey, $30 \%$ workload in the presurvey) and in the postsemester online intervention for the $\operatorname{HRD}(50 \%$ on receiving feedback).

One example of postsemester concerns for the online HRD class (when asked about their expectations for the other class format) was: "My expectations would be that the professor would be more interactive and engaged with the class." Students in both formats seemed to prefer the format they chose for the class; the postsurvey for the face-to-face HRD class was $63 \%$ and $100 \%$ for the online cybersecurity class. They expected more interaction in the online format of the nontechnical class ( $66 \%$ postsurvey for the online HRD group) but expected to learn more in the technical face-to-face class $(40 \%$ in the online cybersecurity postsurvey).

Another example of these concerns was mentioned by a participant on the postsurvey for the online cybersecurity class; when asked about their expectations for the face-to-face class (other format), they replied: "I would expect more real-life scenarios and a more in-depth learning outcomes [sic] with the hands-on labs. As well as more feedback and direction and focus on important material." Grade expectations seemed to be higher for the technical class, regardless of the format, with $88 \%$ of face-to-face students and $90 \%$ of online students "expecting an A." 
Table 3

Preliminary Analysis of Categories/Themes Shared by Both Classes and Formats

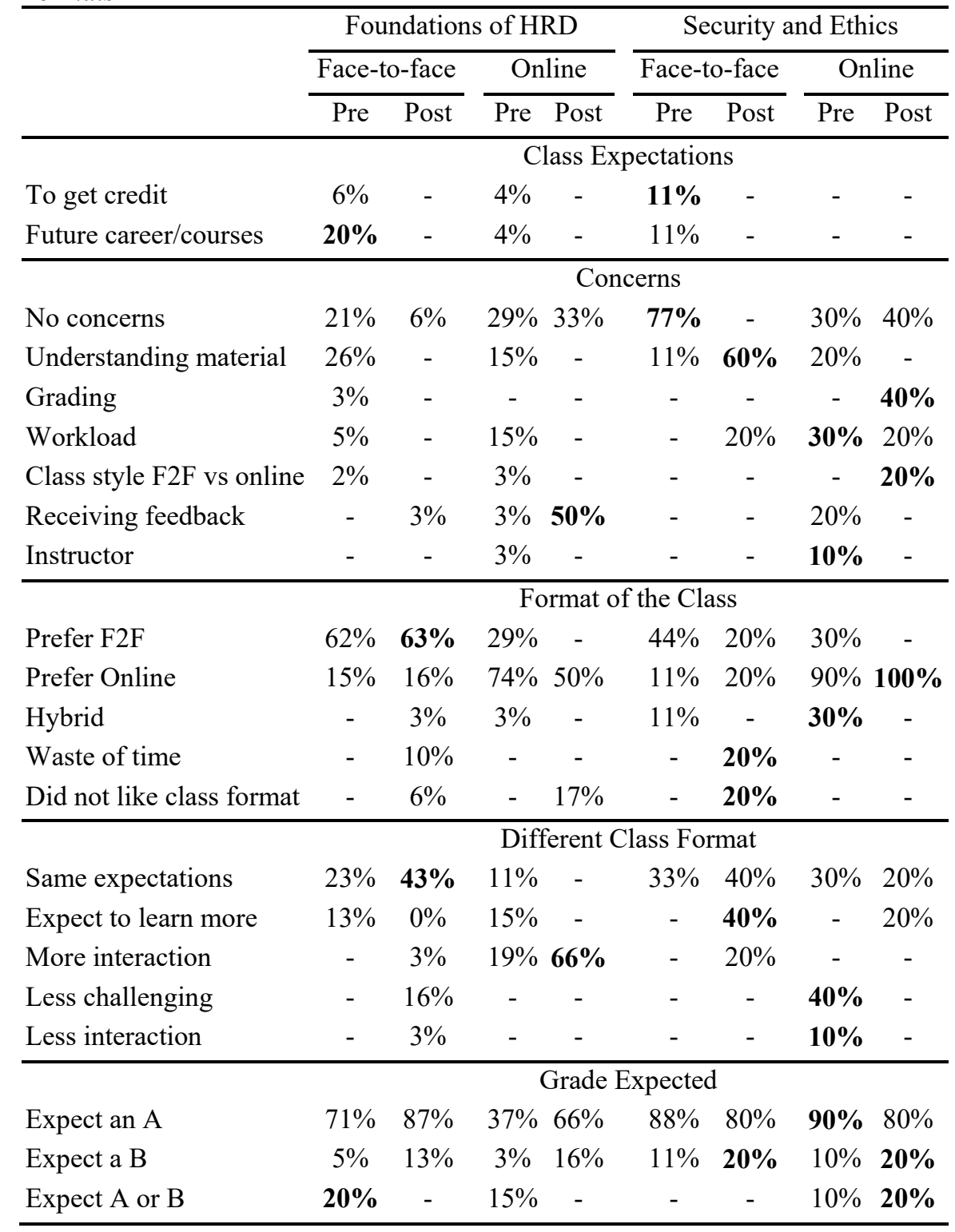


Table 4

Analysis of Exclusive Information for the HRD Nontechnical Class

\begin{tabular}{lcccccc}
\hline & Survey & \multicolumn{2}{c}{ F2F } & & \multicolumn{2}{c}{ Online } \\
\cline { 7 - 8 } \cline { 6 - 7 } & Itememe & Pre & Post & Pre & Post \\
\hline To learn how to teach HRD & 1 & $\mathbf{6 \%}$ & - & - & - \\
To learn how to hire and recruit & 1 & - & - & $\mathbf{4 \%}$ & - \\
Business aspect of HRD & 1 & $\mathbf{3 \%}$ & - & - & - \\
Management & 1 & $\mathbf{6 \%}$ & - & - & - \\
To learn how to train & 1 & $\mathbf{8 \%}$ & - & - & - \\
To learn to be responsible & 1 & - & - & $\mathbf{4 \%}$ & - \\
To learn how to interact with people & 1 & - & - & $\mathbf{4 \%}$ & - \\
Well conveyed information from instructor & 1 & - & $3 \%$ & $4 \%$ & $\mathbf{3 3 \%}$ \\
No expectations & 1 & - & $\mathbf{3 \%}$ & - & - \\
Class be easy to navigate & 1 & $\mathbf{1 3 \%}$ & $3 \%$ & - & - \\
Get more instructor feedback & 2 & - & - & - & $\mathbf{5 0 \%}$ \\
Being presented to by students & 2 & $21 \%$ & $\mathbf{2 3 \%}$ & - & - \\
Confusion & 2 & $15 \%$ & $\mathbf{2 6 \%}$ & $11 \%$ & - \\
Working in a group & 2 & - & - & $\mathbf{3 \%}$ & - \\
Not an engaging environment & 3 & - & $\mathbf{3 \%}$ & - & - \\
Active learning model & 3 & - & $\mathbf{3 \%}$ & - & - \\
No preference & 3 & $\mathbf{2 1 \%}$ & $3 \%$ & - & - \\
More in-depth & 3 & - & - & $\mathbf{2 2 \%}$ & - \\
Self-paced class & 3 & $\mathbf{2 \%}$ & - & - & - \\
Enjoy class more & 3 & $\mathbf{5 \%}$ & - & - & - \\
More detailed instructions & 4 & $5 \%$ & - & $7 \%$ & $\mathbf{3 3 \%}$ \\
More real-life scenarios & 4 & - & - & - & $\mathbf{3 3 \%}$ \\
Traditional format (not active learning) & 4 & $\mathbf{2 \%}$ & - & - & - \\
Higher expectations & 4 & - & - & - & $\mathbf{3 3 \%}$ \\
More resources & 4 & - & $\mathbf{2 0 \%}$ & $7 \%$ & - \\
More in-class time & 4 & $\mathbf{7 \%}$ & - & - & - \\
More work & 4 & $\mathbf{5 \%}$ & - & - & - \\
Confusion & 4 & $\mathbf{5 \%}$ & - & - & - \\
F2F lectures online & 4 & $\mathbf{1 0 \%}$ & - & - & - \\
\hline
\end{tabular}

Note. Survey items by number are shown in Table 1.

Analysis for the HRD (nontechnical) class is shown in Table 4. Given that the majority of participants were located in these classes, the categories exclusive to these groups were more varied and populated. In general terms, this 
table provides more granular information of the results in Table 3. Students' changes in perceptions between pre- and post-survey seemed more relatable to the dissatisfaction about instructor's feedback ( $50 \%$ postsurvey in the online class) as well as the desire for more detailed instructions and more real scenarios ( $33 \%$ on each for the postsurvey in the online class).

Analysis for the cybersecurity technical class is shown in Table 5. The categories shown in this table were specific to the technical class and also provided a more granular analysis. The totality of the respondents for the faceto-face format explicitly stated they expected to learn about cybersecurity at the end of the course ( $100 \%$ postsurvey). The majority of the respondents for the online format felt that the course met their expectations. One example is the following assertion: "Taking this course online, I feared that I wasn't going to be able to learn the material properly, but the hands-on lab and the additional material helped add more understanding than just the textbook" (Postsurvey online cybersecurity student).

Table 5

Analysis of Exclusive Information for the Security and Ethics Technical Class

\begin{tabular}{lcccccc}
\hline & \multicolumn{2}{c}{ Face-to-face } & & \multicolumn{2}{c}{ Online } \\
\cline { 2 - 3 } \cline { 5 - 6 } & Pre & Post & & Pre & Post \\
\hline Expect to learn about cybersecurity & $55 \%$ & $\mathbf{1 0 0} \%$ & & $70 \%$ & - \\
To learn ethics & $22 \%$ & - & & $\mathbf{4 0 \%}$ & - \\
To learn cybersecurity vulnerabilities & - & - & & $\mathbf{1 0 \%}$ & - \\
To learn about digital world & $\mathbf{1 1 \%}$ & - & & - & - \\
To understand human factors with & $\mathbf{1 1 \%}$ & - & & - & - \\
confidential information & & & & & $\mathbf{8 0 \%}$ \\
Course met expectations & - & - & & - & $\mathbf{4 0 \%}$ \\
Course did not meet expectation & - & - & & - & $\mathbf{4 0}$ \\
\hline
\end{tabular}

\section{Quantitative Analysis}

After the perceptions of students were analyzed, the second part of the analysis focused on answering the second research question relating to performance indicators - the grades for each of the sections. Tables 6 and 7 show the descriptive statistics for the four groups, HRD and Cybersecurity courses in both formats. The nontechnical classes' averages were in the $90 \mathrm{~s}$ scale, whereas the technical classes' averages were in the 70s and 80s.

Given the differences in variances, Welch's $t$-tests were used to test for differences between the nontechnical classes (Foundations of HRD). At an alpha level of $\alpha=0.05$, results show that there was no significant difference in terms of performance between the face-to-face and the online formats for the nontechnical class $(t(75)=1.44)$. Similarly, Welch's $t$-tests were used to test for 
differences between the technical classes (Security and Ethics). Results for the technical class show that students in the online format $(M=82.3, V=77.9)$ compared to those in the face-to-face format $(M=75.8, V=95.1)$ demonstrated significantly higher scores, $\mathrm{t}(53)=-2.71, p=.05$.

Table 6

Descriptive Statistics for the Nontechnical Classes (Foundations of HRD)

\begin{tabular}{ccccccccc}
\hline & & & \multicolumn{5}{c}{$95 \%$ CI } \\
\cline { 5 - 7 } & & & & & Lower & Upper & & \\
& $N$ & $M$ & $S D$ & $S E$ & Bound & Bound & Min & Max \\
\hline F2F & 39 & 92.59 & 5.79 & .93 & 90.71 & 94.47 & 71.00 & 100.00 \\
Online & 40 & 90.50 & 6.90 & 1.11 & 88.26 & 92.74 & 76.00 & 100.00 \\
\hline Total & 79 & 91.53 & 6.48 & .73 & 90.08 & 92.98 & 71.00 & 100.00 \\
& & & & & & &
\end{tabular}

Table 7

Descriptive Statistics for the Technical Classes (Security and Ethics)

\begin{tabular}{ccccccccc}
\hline & & & \multicolumn{5}{c}{$95 \%$ CI } \\
\cline { 5 - 8 } & & & & & Lower & Upper & \\
& $N$ & $M$ & $S D$ & $S E$ & Bound & Bound & Min & Max \\
\hline F2F & 27 & 75.77 & 9.75 & 1.88 & 71.90 & 79.62 & 55.71 & 90.00 \\
Online & 33 & 82.08 & 8.86 & 1.54 & 78.93 & 85.22 & 61.43 & 94.29 \\
\hline Total & 60 & 79.24 & 9.72 & 1.25 & 76.73 & 81.75 & 55.71 & 94.29 \\
& & & & & & & & \\
\hline
\end{tabular}

\section{Discussion}

The impacts of delivery modes (i.e., face-to-face and online) on student learning experiences have been extensively studied in the literature. However, the nature of the course content (i.e., technical course contents and nontechnical course contents) as a moderating factor on these impacts has been underinvestigated. In this article, we presented our efforts in addressing this significant gap in the current literature.

We selected two courses (one technical and the other nontechnical) that offered both face-to-face and online sections from a major U.S. university and collected data on the student learning experience. The interpretation of results suggests that students generally preferred the format they selected, showing a level of comfort they had prior to the semester intervention; therefore, it could be assumed that students were familiar with their format of choice. For the nontechnical class, Foundations of HRD, students seemed to share the same concerns as those already reported in the literature, such as lack of instructors' feedback or lack of real-world scenarios. Students in both formats of the Foundations of HRD class outperformed students in the technical class. Students in both formats of the Foundations of HRD class were also more vocal than 
students in the technical class, who tended not to share their post-intervention perceptions. Regardless of the format, students in the technical classes were more concerned about learning, grades, and assignments than students in the nontechnical classes.

The grade performance for students in the online technical class was significantly higher than that of the students in the face-to-face technical class (with a mean 6.31 percentage points higher). This may be explained by the following:

1. Students in the technical online environment are more tech-oriented and, therefore, could be more proficient and resourceful when it comes to technical content, or

2. Students in technical online environments are less time-constrained, not bound by class meeting time, and, therefore, could invest more time.

This result is a new contribution to the existing literature of online vs. faceto-face environments (e.g., Bernard et al., 2004; Sitzmann et al., 2006) in which students' learning attitudes and performance in technical vs. nontechnical courses had not been explicitly studied. Literature in the field of online training is consistent in the way that online classes are perceived as being flexible but with equivalent accountability (Mupinga et al., 2006; Chen et al., 2010). It is somewhat surprising that when it comes to technical content, the expectations of better quality increase. For example, when asked about perceptions about the format other than the one chosen on the postsurvey, one student in the Security and Ethics class replied: "I would want more involvement in terms of lectures. My peers in the online section said that it's just looking at the PowerPoint, and that's it. More involvement for online would be beneficial."

Moving technical and nontechnical content to an online format has repercussions. It could be assumed that students enter the cyber or physical classroom with attitudes and perceptions that do not always hold true when compared to their actual performance. More specifically, speaking about nontechnical content, students were more open to raising concerns, but their actual performance was graded high. It can also be assumed that technical content seems to add concerns for students overall and that those concerns seem to hold true, specifically for those students in the face-to-face format, given the constraints of a traditional classroom for a highly technical class.

Educators can apply these findings by realizing that students who select a particular course type and delivery mode may well carry with them different expectations and attitudes than those who select a different delivery course or a different delivery mode. Since there was an indication of students having been comfortable with their course's mode of delivery, an implication may be that when students are forced to take a course in a non-preferred delivery mode, as has happened often during the COVID-19 pandemic, educators should not 
expect students to have the same degree of comfort. Educators can also use these results when planning a technical course transition from traditional F2F to an online format. An online format is nontraditional for many courses focused on technical content, yet students in online technical courses may have increased expectations of better quality. With the opportunities that synchronous and asynchronous online education afford, especially in COVID-19 times, educators worldwide should be well versed in educational technologies that facilitate different instructional formats

There were several limitations of this study, including the preexisting differences between groups, the assumed equivalence in the way instructors approached instruction, as well as the instructional design for each class. Further analysis should consider these important aspects of traditional and online instruction. Given the widespread perception that technology management belongs in the social sciences, the location of the program in the College of Education may also add another layer of complexity.

Regardless of these limitations, the authors consider this analysis a contribution to the conversation already occurring regarding technical content in online formats. The literature is indeed scarce about online technical instruction.

\section{References}

Bernard, R. M., Abrami, P. C., Lou, Y., Borokhovski, E., Wade, A., Wozney, L., Wallet, P. A., Fiset, M., \& Huang, B. (2004). How does distance education compare with classroom instruction? A meta-analysis of the empirical literature. Review of Educational Research, 74(3), 379-439. https://doi.org/10.3102/00346543074003379

Bir, D. D. (2019). Comparison of academic performance of students in online vs traditional engineering course. European Journal of Open, Distance and Elearning, 22(1), 1-13. https://doi.org/10.2478/eurodl-2019-0001

Bourne, J., Harris, D., \& Mayadas, F. (2005). Online engineering education: Learning anywhere, anytime. Journal of Engineering Education, 94(1), 131-146. https://doi.org/10.1002/j.2168-9830.2005.tb00834.x

Chen, P.-S. D., Lambert, A. D., \& Guidry, K. R. (2010). Engaging online learners: The impact of web-based learning technology on college student engagement. Computers \& Education, 54(4), 1222-1232. https://doi.org/10.1016/j.compedu.2009.11.008

Creswell, J. W., \& Poth, C. N. (2017). Qualitative inquiry \& research design: Choosing among five approaches (4th ed.). Sage.

Downs, H. A. (2014). Evaluation in STEM online graduate degree programs in agricultural sciences and engineering. Journal of Case Studies in Education, 5. https://www.aabri.com/manuscripts/131689.pdf 
Driscoll, A., Jicha, K., Hunt, A. N., Tichavsky, L., \& Thompson, G. (2012). Can online courses deliver in-class results? A comparison of student performance and satisfaction in an online versus a face-to-face introductory sociology course. Teaching Sociology, 40(4), 312-331. https://doi.org/10.1177/0092055X12446624

Ernst, J. V. (2008). A comparison of traditional and hybrid online instructional presentation in communication technology. Journal of Technology Education, 19(2), 40-49. https://scholar.lib.vt.edu/ejournals/JTE/v19n2/pdf/ernst.pdf

Froyd, J. E., Wankat, P. C., \& Smith, K. A. (2012). Five major shifts in 100 years of engineering education. Proceedings of the IEEE, 100, 1344-1360. https://doi.org/10.1109/JPROC.2012.2190167

Lincoln, Y. S., \& Guba, E. G. (1985). Naturalistic inquiry. Sage.

Herron, R. I., Holsombach-Ebner, C., Shomate, A. K., \& Szathmary, K. J. (2012). Large scale quality engineering in distance learning programs. Journal of Asynchronous Learning Networks, 16(5), 19-35. http://dx.doi.org/10.24059/olj.v16i5.289

Holsti, O. R. (1969). Content analysis for the social sciences and humanities. Addison-Wesley.

Huang, X., Zou, Y., Chen, X., Parsaei, H., \& Song, G. (2015). A Comparative Study of Online and Onsite Engineering Experiments. In E-Learn: World Conference on E-Learning in Corporate, Government, Healthcare, and Higher Education (pp. 207-213). Association for the Advancement of Computing in Education.

Mupinga, D. M., Nora, R. T., \& Yaw, D. C. (2006). The learning styles, expectations, and needs of online students. College Teaching, 54(1), 185189. https://doi.org/10.3200/CTCH.54.1.185-189

Ndahi, H. (2006). The use of innovative methods to deliver technology education laboratory courses via distance learning: A strategy to increase enrollment. Journal of Technology Education, 17(2), 33-42. https://doi.org/10.21061/jte.v17i2.a.3

Saleheen, F., Wang, Z., Picone, J., Butz, B. P., \& Won, C.-H. (2018). Efficacy of a virtual teaching assistant in an open laboratory environment for electric circuits. Advances in Engineering Education, 6(3), Article 5. https://advances.asee.org/wp-content/uploads/vol06/issue03/Papers/AEE22-Salaheen.pdf

Sitzmann, T., Kraiger, K., Stewart, D., \& Wisher, R. (2006). The comparative effectiveness of web-based and classroom instruction: A meta-analysis. Personnel psychology, 59(3), 623-664. https://doi.org/10.1111/j.17446570.2006.00049.x

Texas A\&M University. (2018a). EHRD 203 Foundations of Human Resource Development [Fall 2018 course syllabus]. Retrieved from Texas A\&M website: http.tamu.edu 
Texas A\&M University. (2018b). TCMG 308 Security and Ethics in the Digital World [Fall 2018 course syllabus]. Retrieved from Texas A\&M website: http.tamu.edu

Texas A\&M University, Department of Educational Administration and Human Resource Development. (2019). B.S. in Technology Management: Overview. https://eahr.tamu.edu/academics/technology-management/ Wladis, C., Conway, K. M., \& Hachey, A. C. (2015). The online STEM classroom - Who succeeds? An exploration of the impact of ethnicity, gender, and non-traditional student characteristics in the community college context. Community College Review, 43(2), 142-164. https://doi.org/10.1177/0091552115571729

\section{About the Authors}

Noemi Mendoza-Diaz (nmendoza@tamu.edu) is an Assistant Professor in the Department of Educational Administration \& Human Resource Development at Texas A\&M University.

Bin Mai (binmai@tamu.edu) is an Assistant Professor in the Department of Educational Administration \& Human Resource Development at Texas A\&M University.

Jessica Martinez (jessica.martinez@tamu.edu) is a Doctoral Student in the Department of Educational Administration \& Human Resource Development at Texas A\&M University.

Sami Jabarkhail (samij@tamu.edu) is a Doctoral Student in the Department of Educational Administration \& Human Resource Development at Texas A\&M University.

Deyanira Garcia (deyagarcia@tamu.edu) is a Doctoral Student in the Department of Educational Administration \& Human Resource Development at Texas A\&M University. 